\title{
THE ORGAN DONOR CRISIS!
}

\section{THE MISSED ORGAN DONOR POTENTIAL FROM THE ACCIDENT AND EMERGENCY DEPARTMENTS.}

\author{
Paula Aubrey ${ }^{1}$, Sara Arber ${ }^{2}$ and Michelle Tyler ${ }^{3}$
}

\section{Corresponding Author}

${ }^{1}$ Paula Aubrey, RN, MSc, BSc, Regional Donor Transplant Coordinator for North Thames Region, London . 50 Eastbourne Terrace, Paddington ,London W2 6LX / Doctoral student Department of Sociology, University of Surrey, Guildford, Surrey, GU2 7XH, UK

Fax: 02077255600 Phone: 02077252774

Email : paula.aubrey@chelwest.nhs.uk / P.Aubrey@surrey.ac.uk

${ }^{2}$ Professor Sara Arber, BSc, MSc, PhD, Department of Sociology, University of Surrey, Guildford, Surrey, GU2 7XH, UK

${ }^{3}$ Michelle Tyler, RN, DipH ed, Regional Donor Transplant Coordinator for North Thames Region, London . 50 Eastbourne Terrace, Paddington, London W2 6LX 


\section{Authors: Paula Aubrey ${ }^{1}$, Sara Arber ${ }^{2}$ and Michelle Tyler ${ }^{3}$ \\ The Organ Donor Crisis!}

The missed organ donor potential from the Accident and Emergency Departments.

Abstract. The critical shortage of cadaveric donor organs for transplant purposes is a worldwide concern. The disparity between the number of cadaveric organs donated for transplant purposes and those patients awaiting transplant operations continues to widen.

This paper reports on the findings of an audit of deaths undertaken in ten Accident and Emergency (A\&E) Departments in North Thames Region, UK. The audit itself was borne out of informal anecdotal accounts from colleagues working in the A\&E department who suggested that there was a potential pool of organ and tissue donors that were not being realised.

When a person dies the tragedy is in the death not in the donation of organs. It's as simple as this; a missed donor is a missed opportunity for a patient to receive a life enhancing, life saving transplants.

The paper discusses how those audit findings have helped shape the current A\&E education strategy in the North Thames Region. The result has been that the North Thames Region has seen a dramatic increase in the number of referrals from the A\&E Department resulting in solid organ transplantation (figure 1). Although the results are very encouraging the programme is still very much in its infancy and a long way from the desired $100 \%$ referral rate.

In order to maximise the number of organs from the potential donor pool the transplant community needs to focus more attention towards donation from the A\&E departments.

\section{Introduction}

Despite many initiatives to increase the number of cadaveric organs for transplant a critical shortage still remains (1). Although the organ donation rates vary across the UK, during 
2005 2006 United Kingdom Transplant (UKT) reported that there were 764 cadaveric donors of solid organs in the U.K, a $4 \%$ decrease from the previous year (2). Another major concern is the family refusal rate which is higher than previously thought, North Thames having the highest in the country. The overall refusal rate reported in 2006 for the UK was $40 \%$ and $52 \%$ in the North Thames area (2).

At the end of the last financial year 2006/7, UK Transplant reported that there were 7,219 patients awaiting transplants in the UK alone (3). Between 2005 2006, there were 6,698 patients awaiting a transplant, of which 483 died (2).

\section{Audit of deaths in A\&E Departments.}

Between October 2004 and December 2005, Aubrey ${ }^{1}$, as part of her transplant coordinators role, undertook a retrospective audit of deaths from ten A\&E departments in the North Thames Region to determine the potential of heart beating organ donors and controlled non heart beating donors. Initially four units took part in the pilot stage. The results were very encouraging which led to a further six departments been invited into the audit. Each A\&E department who were approached agreed enthusiastically to take part in the audit and were very supportive.

The criteria used to identify potential donors was based on UK Transplant criteria for potential heart beating or controlled non heart beating organ donors. (Table 1) Other criteria normally taken into account are consent from family and HM Coroners Permission. All patients who die in the A\&E department fall within the legal remit of the HM Coroner.

Very few people who die in A\&E departments fulfil these criteria, thus not many people who die can donate organs, highlighting the essential need for all potential organ donor families to be approached for donation. 


\section{Audit findings}

The 14 month audit of deaths in ten A\&E departments identified twenty potential solid organ donors. Sixteen potential solid organ donors were retrospectively audited whilst four deaths were identified during a prospective audit. On average a potential of two organ donors from each A\&E department per year was identified. Despite the possibility of family refusal to organ donation, this is a significant number when we calculate the potential across the thirty two A\&E departments in the North Thames Region alone. Two more organ donors from each unit within North Thames would mean that potentially one hundred and twenty eight patients per year will receive kidney transplants and sixty four more donors may provide life saving transplant for patients waiting for liver, heart and lung transplant operations.

Potential organ donors in the A\&E department are patients who die as a result of sudden, traumatic and premature death (see Table 2).

\section{Detailed Audit results}

In total 770 deaths were audited out of 1204 deaths over a fourteen month period in the ten A\&E Departments. The disparity in numbers was due to availability of medical notes and also the change in the age criteria. After the first four hospitals were audited the decision was made not to audit deaths of patients aged 80 years and above. (Table 3 )

\section{Feedback of Audit results to A\&E Colleagues.}

The results of the audit were fed back to staff in the ten A\&E departments who took part in the audit. The findings were also disseminated to health care professional colleagues working in and around the A\&E department who care for both the potential donors and their bereaved relatives. The findings were disseminated both on a one - to one basis and in group sessions using formal and informal presentation. 
Table 4 shows the main barriers to organ donation from A\&E that were cited by health care staff. The barriers cited did not come as any major surprise. The authors of this paper suggest that the main causative factor for non -donation from within the A\&E department in the UK is due to an inadequate A\&E organ donor programme. It has become very clear that in order to address the complexities surrounding organ donation from the A\&E department there is a need for a collaborative exploration of factors amongst key stakeholders.

\section{Educational development programme.}

Following feedback to A\&E staff, action to address and further explore the barriers cited by professional health colleagues working in the A\&E department commenced with immediate effect. All thirty two A\&E departments within North Thames region were provided with contact details for the Donor Transplant Coordinator Team and this is regularly checked and updated.

In order to address and further explore factors that contribute to donation decisions in the A\&E department, it is imperative that key health care professionals who are involved in the care of the potential donor and the bereaved relatives are identified. The key professional are based hospital wide and not just in the A\&E department and therefore gaining access to appropriate educational forums through out the hospital is necessary. The educational forums are used as a platform to provide adequate information and support in order for potential donors to be recognised and referred on to the donor transplant team team.

\section{Identified key personnel are}

- Hospital Consultants - A\&E, Anaesthetic \& Neuro surgeons

- Emergency trauma team

- A\&E nursing and medical Staff

- HM Coroners and HM Coroners Officers

\section{Appropriate educational forums in which to capture the above key health care professionals have been identified as the following:}


- Hospital grand rounds

- Emergency trauma meetings

- Critical care delivery groups

- Critical care networks

- Senior nurse meetings

- Clinical governance meetings

In addition to this, two specialist educational days, sponsored by UK Transplant took place in July 2007 that were attended by key health professionals. Both educational days were very well evaluated by the delegates. In order to continue to measure success and focus the A\&E development strategy, it is intended that the audit of deaths in the A\&E departments will take place annually.

One of the main barriers to organ donation cited by colleagues working in the A\&E department is their lack of confidence and experience in offering donation to acutely bereaved families. This is the focus of Aubrey's ${ }^{1} \mathrm{PhD}$ study.

The A\&E audit findings provided us with a basis to start an A\&E educational development programme, although the programme is in its infancy, the results so far are very encouraging.

The data in Figure 1 shows a significant increase in the number of potential donors referred for donation since 2001. Indeed during the last financial year, 2006 2007, our A\&E colleagues referred twenty three potential donors, fourteen of which resulted in actual solid organ donation. Forty five people patients have undergone life saving transplants as a result of these fourteen donors. The organs transplanted were mainly liver and kidneys, in addition to two double lung transplants, one single lung transplant and one heart transplant. 
Out of the fourteen organ donors who were referred from the A\&E department, five donors were eventually transferred to the intensive care unit. The remaining nine donors were cared for in A\&E resuscitation room before being transferred to the recovery area in the operating theatre department. (Figure 1)

It is standard practice within the North Thames region that when a referral of a potential donor is made from the A\&E department, the DTC will initiate a rapid mobilisation response to attend the department to make an assessment. Where resources permit, a second DTC will attend the A\&E department. One to facilitate and manage the donation process and the second DTC to support the potential donor family.

\section{$\underline{\text { Discussion }}$}

At present, the majority of organ donors in the UK are referred from the intensive care unit (ICU) with a very small number referred from the accident and emergency. It is important to recognise that there are significant situational differences between A\&E and ICU potential donors in relation to both family dynamics and resources available when facilitating the donor referral process.

Resource issues, such as lack of ICU beds, and manpower shortage were cited as some of the barriers to organ donation from the A\&E department. However the biggest internal obstacle from the A\&E department appears to be the lack of confidence of staff in approaching the acutely bereaved relative for organ and tissue donation. Unlike in the intensive care unit (ICU), the family in the A\&E will not have had time to build relationships with the medical and nursing staff, nor have they had any time to come to terms with the acute suddenness of a loved one's illness and premature death.

In the A\&E, the approach for donation consent is likely to be undertaken very soon after the family have been informed of their loved ones' death or inevitable death and there is no time to build a rapport. It is imperative that the health care professionals who are involved in the care of patients who die in the A\&E allow the 
bereaved family to have a choice about organ and tissue donation. It is not a failure if a bereaved family say 'no' to organ donation; however it is a failure if they were never given the choice to say 'yes' or 'no' in the first instance. Equally we know that twenty three percent of the population in the UK have registered their wishes to become an organ donor on the UK Transplant Organ Donor Register (ODR). Not everyone on the ODR dies in the intensive care unit (1)

Preliminary findings suggest that the consent rate for donation when broached in the A\&E department appears to be higher than when broached in the ICU. These preliminary findings (from Aubrey's ${ }^{1}$ current $\mathrm{PhD}$ study) identify that the disparity in consent rate relates to 'finality' and 'hope' in such sad circumstances.

Currently there are no specific 'best practice' guidelines or health care policy on organ donation specific to the A\&E department. It is anticipated that the A\&E educational development strategy programme currently underway in the North Thames Region and in conjunction with Aubrey's research study, will provide a solid foundation for the development of an extensive educational development programme for health care professionals in approaching bereaved relatives for organ donation in the A\&E department. The programme is in its infancy and we have a long way to go before we achieve our $100 \%$ desired referral rate $(4,5)$.

\section{Summary}


The critical shortage of donor organs demands that we explore all areas where there may be a potential for organ donors. Equally a collaborative approach amongst key stakeholders is imperative in order to address the complexities surrounding organ donation from the A\&E department.

The North Thames Regional Donor Transplant Coordinators have identified that a greater potential for solid organ donation does exists within the A\&E departments. The anticipated benefits for potential transplant recipients greatly outweigh any of the complexities associated with A\&E donor referrals, none of which have been proven to be insurmountable.

\section{Acknowledgement}

The authors would like to say thank you to all those who contributed to the retropsective audit of deaths from the ten A\&E departments. 
Aubrey ${ }^{1}$ and Tyler ${ }^{3}$ would like to take this opportunity to say thank to St. John Ambulance, UK and The 2007 Organ and Tissue Donation Congress Committee for the financial support they received in the form of Travel awards which enabled them both to attend The 2007 Organ Donation Congress, Philladelphia.

Aubrey ${ }^{1}$ is currently undertaking a PhD at the Univeristy of Surrey Guildford, under the supervission of Professor Sara Arber, with financial support and Study leave from the North Thames Transplant Coodinator Team. The focus of the study is organ donation from the A\&E departments titled "Exploration of Social and Organisational Factors Influencing Organ Donation From A\&E Departments: The Perspectives of Bereaved Families and Health Care Professionals" 


\section{References}

1. Department of Health (2004) Saving Lives, Valuing donors: a transplant framework for England, London: Department of Health.

2. Department of Health (2006) Transplant Activity in the UK 2005 2006. UK Transplant, London: Department of Health

3. UK Transplant (2007) Weekly statistics www.uktranspant.org.uk Accessed $16^{\text {th }}$ April 2007

4. Aubrey P., Lister S. (2006) The Development of an A\&E Programme. UK Transplant Bulletin. Issue 61

5. Aubrey P. (2007) Increasing the supply of organs for transplant; A retrospective audit of deaths in the accident and emergency, March 2007. Paper presented at the British Trasplantation Society, $11^{\text {th }}$ Congress 
Table 1

Table 1 UK Transplant criteria for potential heart beating or controlled non heart beating organ donors

Brain stem dead / or death inventible

- The body is maintained on a ventilator

- HIV negative

- No family history of CJD

- Active cancer 
Table 2

Table 2 Typical Case Study of potential donor identified during the audit of A\&E deaths

- Young male, aged 22

- Serious head injury / thoracic injuries after a fall

- Medical consensus opinion situation futile

- Brain stem death likely diagnosis

- Active treatment withdrawn

- Length of time in department approx 6 hours.

- Next of Kin present in A\&E (Mother)

- No discussion with Transplant Coordinators 
Table 3. Results of Audit of deaths in 10 A \&E Departments

\begin{tabular}{|l|l|l|l|l|}
\hline Hospital & No & No of & Potential heart & $\begin{array}{l}\text { Potential } \\
\text { heart } \\
\text { donors }\end{array}$ \\
\hline A\&E 1 & of deaths & deaths audited & Peating donoring \\
\hline A\&E 2 & 116 & 116 & 2 & 0 \\
\hline A\&E 3 & 61 & 52 & 2 & 0 \\
\hline A\&E 4 & 50 & 26 & 0 & 0 \\
\hline A\&E 5 & 159 & 106 & 1 & 0 \\
\hline & 177 & 99 & 0 & 1 \\
\hline & & & & \\
\hline A\&E 6 & 176 & 117 & 1 & 1 \\
\hline A\&E 7 & 207 & 120 & 3 & 0 \\
\hline A\&E 8 & 58 & 35 & 2 & 0 \\
\hline A\&E 10 & 85 & 52 & 2 & 0 \\
\hline & 115 & 47 & 1 & 0 \\
\hline Totals & 1204 & 770 & 14 & 2 \\
\cline { 2 - 5 } & & & 16 & \\
\hline
\end{tabular}

NB: A further 4 potential heart beating donors were identified during a prospective audit increasing the actual number of potential donors to 20 . 
Table 4

Table 4. The barriers cited as to why patients may not be recognised as potential donors in the A\&E department included:

- Non recognition of potential donors

- Lack of confidence and experience of A\&E staff in offering the option of donation to acutely bereaved families

- No contact details for Donor Transplant Coordinator

- Shortage of intensive care beds

- HM Coroner involvement

- Limited resources - physical space and manpower 
Figure 1. Donation Activity from A\&E Departments in the North Thames Region, 2001 2006

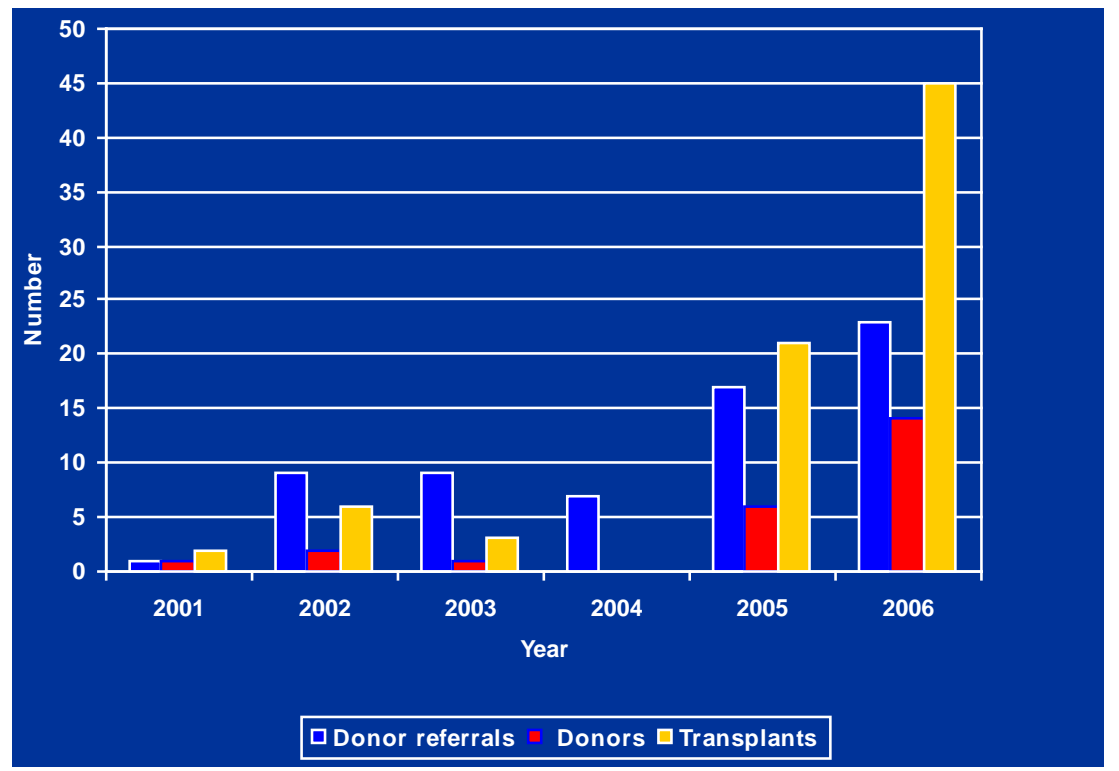

